\title{
A CASE REPORT OF UNICENTRIC CASTLEMAN DISEASE
}

\author{
AKTER $M^{1}$, KHALIL MD I ${ }^{2}$, NABI G $^{3}$, NAZNEEN $S^{4}$, MALLIK MU ${ }^{5}$, BISWAS E $^{6}$, KABIR T $^{7}$
}

\begin{abstract}
:
Castleman disease (CD) or angiofollicular lymph node hyperplasia is an uncommon benign lymphoproliferative disorder. Sometimes it is related to the chronic human herpes virus 8 (HHV-8) infection and the human immunodeficiency virus (HIV). Two clinical entities have been described: a unicentric presentation with the disease confined to a single anatomic lymph node and a multicentric presentation characterized by generalized lymphadenopathy and a more aggressive clinical course. Also, three histopathological subtypes have been described: hyalinevascular, plasma cell, and a mixed variant. We report the case of a 22-year-old young man who was diagnosed as unicentric Castleman Disease. We found on routine physical examination a mass localized in the left abdomen without clinically important constitutional symptoms for 3 years. Abdominal ultrasound and computed tomography scans revealed minimally enhancing soft tissue density lesion \& it was seen in the left para aortic region measuring about $71 \mathrm{~mm} x$ $42 \mathrm{~mm}$ in size. The patient subse-quently underwent an exploratory laparotomy. After opening of the abdomen, a lump measuring about $8 \mathrm{~cm} \times 5 \mathrm{~cm}$ was found in the mesentery. The whole lump was dissected out and the gap in the mesentery was closed. No other lymphadenopathy was found. The specimen was sent for histopathology which revealed Castleman disease, plasma cell type. The patient completely recovered after surgery. Castleman disease is commonly misdiagnosed as malignant lymphoma, lymphadenitis or ectopic thymoma. So far, its diagnosis is mainly achieved via histopathological examination of surgically obtained tissue. Local or unicentric $C D$ has a good prognosis if surgically excised properly.
\end{abstract}

Key Words: $C D$ (Castleman disease), MCD(multicentric Castleman disease), LCD (localized castleman disease.)

J Dhaka Med Coll. 2014; 23(2) : 256-258.

\section{Case report:}

A 22 years young man presented to surgery OPD with the complaints of gradually increasing painless abdominal lump for 3 years.

His bowel and bladder habit was normal. He had no history of fever, anorexia, weight loss, constipation, diarrhoea, abdominal pain or abdominal distension. Physical examination revealed the presence of an $8 \times 10 \mathrm{~cm}$ welldefined nontender mass with a smooth surface in the left abdomen. On percussion it was dull over the mass. His vital parameters were normal. There was no other palpable lymph nodes.

An abdominal ultra-sound \& computed tomography (CT) scan of his abdomen revealed minimally enhancing soft tissue density lesion in the left para aortic region measuring about $71 \mathrm{~mm} \times 42 \mathrm{~mm}$ in size, consistant with enlarged lymph node.

After taking written informed consent he was underwent exploratory laparotomy. After opening of the abdomen, a lump measuring

1. Dr. Mafruha Akter, Assistant Professor, Bone Marrow Transplant Unit, Department of Haematology, Dhaka Medical College Hospital, Dhaka.

2. Dr. Ibrahim Khalil, Assistant Professor, Surgery Unit, DMCH, Dhaka

3. Dr. Golam Nabi, Assistant Professor, Department t of Medicine, Z.H. Sikder Women's Medical College, Dhaka

4. Dr. Syed Zakir Hossain, Assistant Professor, Department t of Medicine, DMCH, Dhaka

5. Dr. Md. Uzzwal Mallik, Department of Medicine, Dhaka Medical College Hospital, Dhaka.

6. Dr. Eshita Biswas, Medicine Specialist, United Hospital, Dhaka

7. Dr. Tania Kabir, Registrar, Medicine Unit-2, Dhaka Medical College Hospital, Dhaka.

Correspondence: Dr. Mafruha Akter, Assistant Professor, Bone marrow transplant unit, Department of Haematology, Dhaka Medical College Hospital, Dhaka. E-mail: mafruha673@gmail.com 
about $8 \mathrm{~cm} \times 5 \mathrm{~cm}$ was found in the mesentery. The whole lump was dissected out and the gap in the mesentery was closed. No other lymphadenopathy was found. The specimen was sent for histopathology which revealed Castleman disease, plasma cell type. The patient completely recovered after surgery.

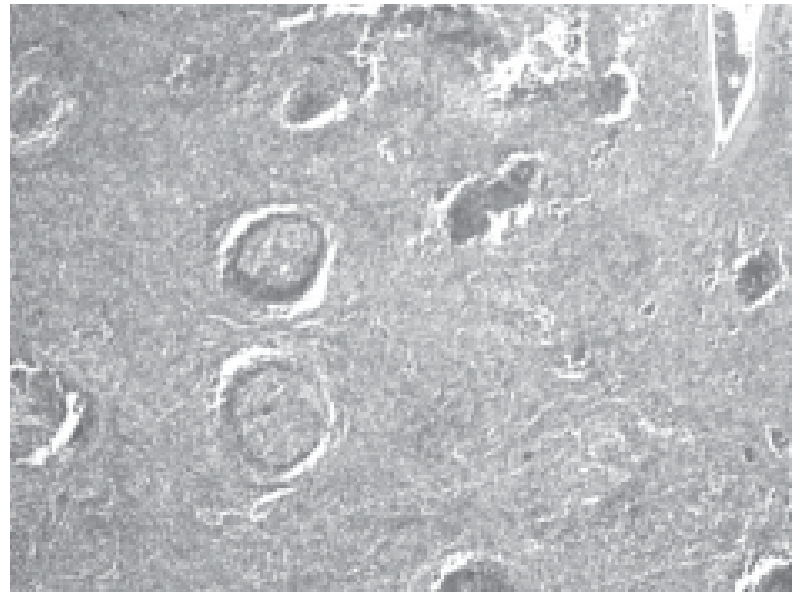

Fig.-1

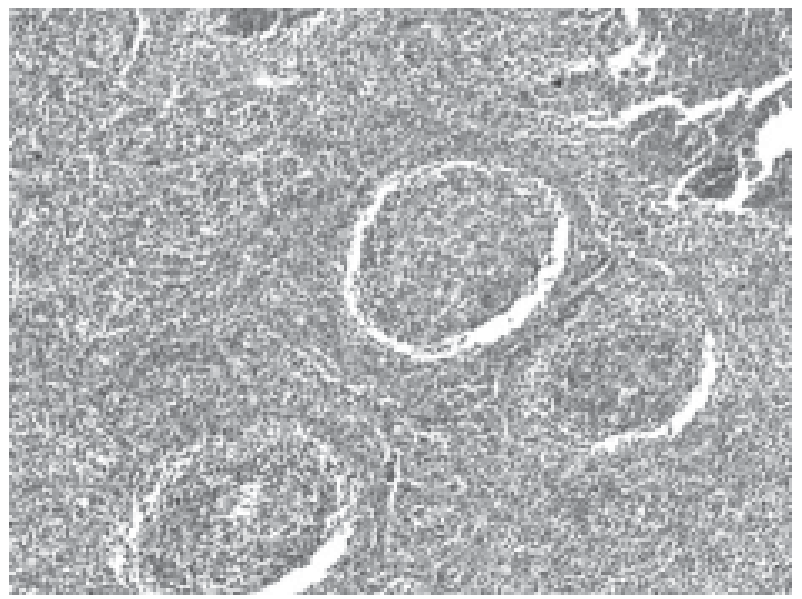

Fig.-2

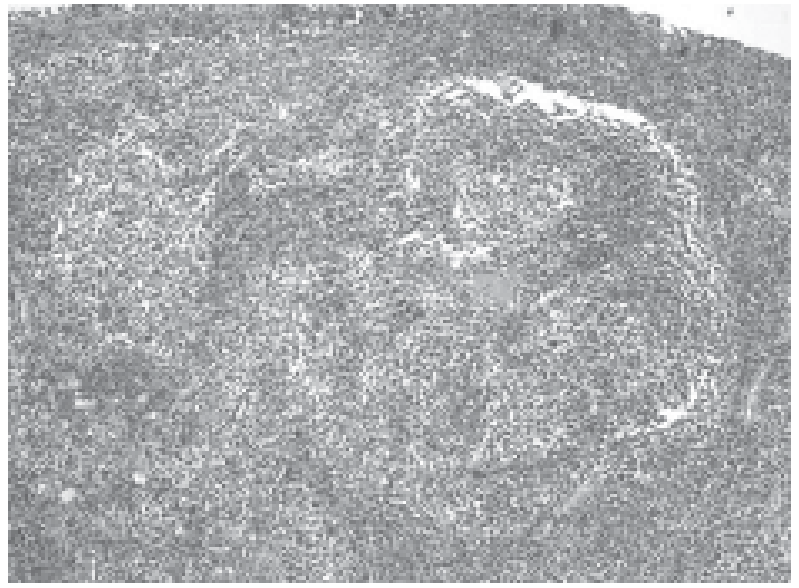

Fig.-3

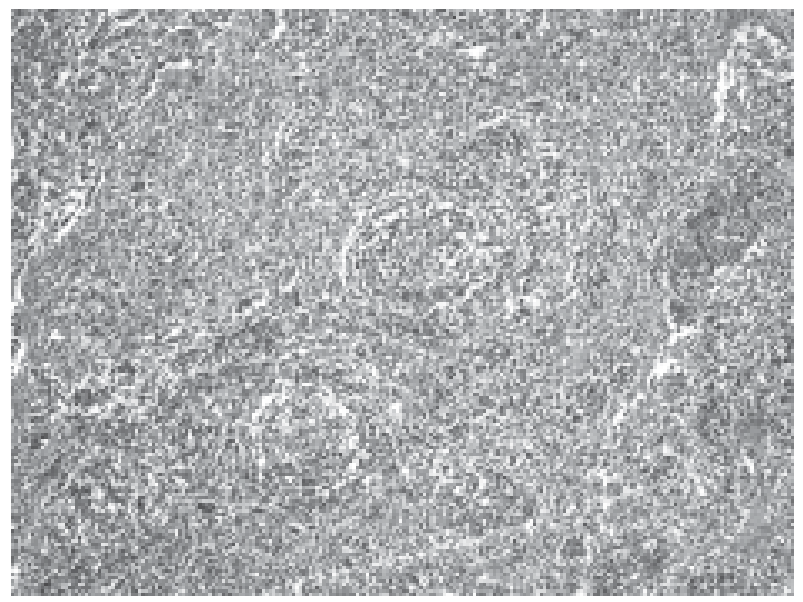

Fig.-4

\section{Discussion:}

Castleman disease is a rare variety of benign hypertrophy of lymphoid tissue. It is regarded as a pre lymphomatous condition. The disease was first described in 1956 by Benjamin Cattleman,who identified a group of patients with solitary hyperplasic mediastinal lymph nodes with small germinal center ${ }^{1}$. Although the etiology of $\mathrm{CD}$ remains unclear, the pathogenesis is related to an abnormal immune response to viral infections or medication side effects that can cause similar changes in hyperplastic reactive lymph nodes ${ }^{2}$. The hepatitis B and Epstein-Barr viruses and HIV are the result of the immune perturbation that may be seen with $\mathrm{CD}^{4}$.

Some studies found that inflammatory cytokines were associated with the manifestation of a variety of symptoms accompanying $\mathrm{CD}$, especially for plasma cell type or multicentric CD (MCD). There are 3 types of CD: hyaline vascular type, plasma cell type and mixed type[3].Unicentric hyaline vascular $\mathrm{CD}$ is the most common histological form of the disease. However clinically, according to the involved range it can be divided into 2 types: MCD and local CD (LCD) ${ }^{3}$.

The clinical features of LCD are painless enlarged lymph nodes, usually localized in the mediastinum, cervical, axillary lymph nodes or abdomen; it may also occur in the muscles, larynx and lungs and orbits where no lymph nodes exist. Some patients experience fever, sweat, fatigue, anorexia and substantial weight loss. 
Laboratory examinations reveal increased serum iron protein and inflammatory proteins of polyclonal hyperimmunoglobulinia and CRP, decreased serum iron and total iron-binding capacity and increased interleukin (IL)-6. Coombs test auto antibodies and rheumatoid factors may be positive.

Routine blood tests usually reveal anaemia, raised ESR, thrombocytopenia and raised polyclonal gamma globulins. Identifying an immunophenotypically varied population of Blymphocytes with polyclonal surface and cytoplasmic immunoglobulin markers helps to confirm the diagnosis of Castleman's disease and differentiate it from lymphoma ${ }^{5}$. HIV testing should be undertaken. Herpes Virus (HHV 8/KSHV) has been isolated in almost all cases of HIV associated Kaposi's sarcoma MCD and some non HIV Kaposi's sarcoma MCD prompting tests for KSHV[6]. Histological examination of the biopsied lymph node is essential for the diagnosis. Histologically the main types are:

- The hyaline vascular type characterized by lymphoid follicular proliferation at different levels of maturity, often forming a layered or 'onionskin' pattern surrounding a hyalinised vessel at the center of the follicle. These vessels are often prominent and reactive. This is more commonly seen in the localized form of the disease.

- The plasma cell variant has sheets of mature plasma cells within the interfollicular tissues surrounding larger germinal centers and has significantly less vascularity.

- A third histological variant showing a mixed picture can also be seen in MCD.
Localized CD usually has a good prognosis and requires surgical excision of the enlarged lymph node with no further treatment. The patients generally remain asymptomatic thereafter. MCD however tends to have a variable prognosis with no documented treatment consensus. A variety of combination treatments have been tried with surgical excision, chemotherapy and steroids.

\section{Conclusion:}

The aim of the discussion is to revisit the rare clinicopathological diagnosis of Castleman disease, its treatment and prognosis. The unicentric variety is of good prognosis overall.

Photo courtesy: Prof Md Golam Mostafa (Pathology)

\section{References:}

1. B. Castleman, L. Iverson, and V. P. Menedez, "Localized mediastinal lymph node hyperplasia resembling thymoma," Cancer, vol. 9, pp. 822830, 1956.

2. Sun H, Wang R, Bin H, et al. Localized Castleman disease with paraneoplastic pemphigus and pulmonary involvement: clinical features and histopathology [article in Chinese] Zhonghua Yi Xue Za Zhi. 2002;82:530-3. [PubMed]

3. Cobzeanu MD, Rusu D, Negru D, et al. Castleman disease of the neck. Rev Med Chir Soc Med Nat Iasi. 2005;109:567-72. [PubMed]

4. Ning L, Fa-Bo Q, Feng DL. Epidemiological and clinical characteristics of Castleman's disease. World Chinese Journal of Digestology. 2008;16:3469-73.

5. McCarty MJ, Svetislava JV, Banks PM, et al. Angiofollicular lymph node hyperplasia (Castleman's disease).Cancer Treat Rev 1995; 21:291-310.

6. Soulier J, Grollet L, Oksenhendler E, et al. Kaposi's sarcoma-associated herpervirus-like DNA sequences in multicentric Castleman's disease.Blood 1995;86(4):1276-80. 